\title{
Cancer risks among long-standing spouses
}

\author{
K Hemminki*,' and Y Jiang' \\ 'Department of Biosciences at Novum, Karolinska Institute, 14157 Huddinge, Sweden
}

We estimated risks for concordant and discordant cancers in spouses in order to quantify cancer risks from the shared environment. The study was restricted to spouses who had one or more children in common and who lived together for at least 15 years after the first child's birth. The nation-wide Family-Cancer Database was used as the source of family and cancer data. Standardised incidence ratios were calculated for concordant and discordant cancers in spouses after 50 years of age. Among the 18 cancer sites considered, only three sites, stomach, lung and bladder, showed concordant increases of cancer among spouses, standardised incidence ratios ranging only from I.19 to 1.38. Additionally, gastric and pancreatic cancer were associated among spouses, as did many cancers which were related to tobacco smoking or human papilloma virus infection. By contrast, standardised incidence ratios of colon, rectal, renal and skin cancers showed no increases among spouses. Shared lifestyle among family members seems to explain only a small proportion of familial cancer susceptibility. Because lifestyles are likely to differ more between parents and offspring than between spouses, familial cancer risks between parents and offspring are even more likely to be due to heritable than environmental effects.

British Journal of Cancer (2002) 86, 1737- 1740. doi:I0.1038/sj.bjc.6600302 www.bjcancer.com

(C) 2002 Cancer Research UK

Keywords: cancer in spouses; familial cancer; heredity; genetic epidemiology

Many lines of epidemiological evidence indicate that cancer is mainly an environmental disease (Doll and Peto, 1981; IARC, 1990; Lichtenstein et al, 2000; Peto, 2001). During the past decade it has become increasingly clear that overweight and lack of physical activity convey a risk of cancer, which may account for $5 \%$ of all cancers in Europe (Bergstrom et al, 2001; IARC, 2002). Moreover, the risks at the population level caused by various infections have become better understood, and the known infections have been estimated to account for $15 \%$ of cancer worldwide, though less in Europe (Pisani et al, 1997; Zur Hausen, 1999). In spite of the enormous research effort on diet and cancer, the proportion of cancer attributable to diet or to any specific dietary component remains speculative. It has been estimated that at least $50 \%$, and probably as much as $70 \%$ of cancer deaths are unavoidable among non-smokers mainly because their aetiology remains unknown (Peto, 2001).

Decades long cohabitation by spouses should tend to result in many habits and carcinogenic exposures being similar. Interest in disease among spouses earlier focused on sexually transmitted diseases and the effects of passive smoking (IARC, 1995; Hackshaw, 1998; Hemminki et al, 2000a; Hemminki and Dong, 2000a). Besides assessing life-style factors and cancer risks, they can point to the environmental contribution to the familial aggregation of cancer, and they thus help to apportion heritable effects (Hemminki et al, 2001a,d). The studies from the Swedish Family-Cancer Database have shown limited spouse concordance, affecting mainly the sites of known environmental carcinogens (Hemminki and Dong, 2000b; Hemminki et al, 2001a). However, in the previous studies the length of cohabitation between the spouses was not

*Correspondence: K Hemminki, CNT Novum, I4I 57 Huddinge, Sweden; E-mail: Kari.Hemminki@cnt.ki.se.

Received 20 December 200 I; revised II March 2002; accepted I5 March 2002 considered, nor were any adjustments for socio-economic status carried out. We address these shortcomings here in a study of the 2001 update of the Family-Cancer Database, covering 10.2 million individuals and over one million tumours (Hemminki et $a l, 2001 c)$. In addition to concordant cancers in spouses, a systematic analysis of discordant cancers was also carried out.

\section{METHODS}

The Swedish Family-Cancer Database includes persons born after 1932 with their biological parents (Hemminki et al, 2001c) together with cancers retrieved from the nationwide Swedish Cancer Registry for the years 1958 to 1998 . Additionally, residential and socioeconomic data were included from national censuses, carried out in 1960, 1970, 1980 and 1990. A four-digit diagnostic code according to a modified version of the seventh revision of the International Classification of Diseases (ICD-7) was used. The following sites were examined collectively: 'upper aerodigestive tract', lip, mouth and pharynx (codes 140,141,143-148) and leukemia (204207), polycythemia vera (208) and myelofibrosis (209). Skin cancer only included squamous cell carcinoma; basal cell carcinoma is not registered in the Cancer Registry.

Spouses were defined as the parents of the woman's first child, and they had to live in a shared address in at least two subsequent decennial censuses; thus the minimal cohabitation was 15 years by average. Even though data were available on the marital status, the above definition was preferable because many couples live together without being married. Follow-up was started at the age of 50 years, to allow latency time from the start of cohabitation. Standardized incidence ratios (SIRs) were calculated as the ratio of observed (O) to expected (E) number of cases. The expected numbers were calculated from site-, age-, period (10-year bands), area (three areas, three large cities, south Sweden and the rest), socio-economic status (manual workers, 'intermediate' workers, professionals and others) - and sex-standardized rates (Esteve et 
al, 1994). SIRs for women were additionally adjusted for parity (one or more; all women were parous) and age at first birth $(<20,20-29$ or more years). SIRs were calculated for a spouse when the partner, proband, presented with the same, concordant, or another, discordant cancer. The reference group was spouses without cancer. Confidence intervals (95\% CI) were calculated assuming a Poisson distribution (Esteve et al, 1994).

In analysis of discordant sites for cancers occurring in both genders, four comparisons were possible, i.e., (1) gastric cancer in husband by pancreatic cancer in wife; (2) pancreatic cancer in husband by gastric cancer in wife; (3) gastric cancer in wife by pancreatic cancer in husband; (4) pancreatic cancer in wife by gastric cancer in husband. The number of affected pairs is identical in (1) and (3), and also in (2) and (4); the calculated SIRs were often quite similar. However, (1) and (2), and also (3) and (4) were entirely independent analyses, and the results in this study have only been presented if some consistency was found in more than one type of analysis. This was a useful safeguard against false positive findings (Dong and Hemminki, 2001).

\section{RESULTS}

A total of 71020 couples presented with a concordant or discordant cancer after age 50 years, who fulfilled the entrance criteria for the study of being parents to the first child of the women and residing in a shared address at least through two consecutive censuses after the first childbirth. In Table 1, we show usefulness of the approach, by comparing cancer sites among spouses where increased risks should be expected due to shared smoking and sexual habits. When wives were probands and presented with lung cancer, husbands had increased risks of oesophageal (SIR 1.47), pancreatic (1.30), laryngeal (1.74) and lung (1.38) cancers. Cervical cancer was associated with pancreatic (1.28), laryngeal (1.53), lung (1.44) and penile (1.88) cancers in the husband. When husbands presented with a larynx cancer, their wives had an excess of lung (1.58) and cervical cancer (1.45). Lung cancer in husbands was associated with lung (1.32), cervical (1.31) and bladder (1.16) cancer in wives. Penile cancer was associated with cervical cancer in the wife (1.84).

Risks for spouses for concordant cancers are shown in Table 2 for sites where more than five pairs were recorded. Cancer at three sites was increased for husbands by cancer in wives: gastric (SIR 1.25), lung (1.38) and bladder (1.24) cancers. Because of the large

Table I Aggregation of tobacco- and sexual behaviour-related cancers among spouses

\begin{tabular}{llrrc}
\hline Proband: Wife & Cancer in husband & $\mathbf{0}$ & SIR & $\mathbf{9 5 \% ~ C I}$ \\
\hline Lung & Esophagus & 48 & 1.47 & $1.08-1.92$ \\
& Pancreas & 114 & 1.30 & $1.07-1.55$ \\
& Larynx & 49 & 1.74 & $1.30-2.26$ \\
& Lung & 406 & 1.38 & $1.25-1.52$ \\
Cervix & Pancreas & 115 & 1.28 & $1.05-1.52$ \\
& Larynx & 51 & 1.53 & $1.13-1.99$ \\
& Lung & 458 & 1.44 & $1.31-1.58$ \\
& Penis & 19 & 1.88 & $1.13-2.86$ \\
Proband: Husband & Cancer in wife & $\mathbf{0}$ & $\mathbf{S I R}$ & $\mathbf{9 5 \%} \mathbf{C I}$ \\
\hline \multirow{2}{*}{ Larynx } & Lung & 49 & 1.58 & $1.17-2.06$ \\
& Cervix & 51 & 1.45 & $1.08-1.88$ \\
Lung & Lung & 406 & 1.32 & $1.20-1.46$ \\
& Cervix & 458 & 1.31 & $1.20-1.44$ \\
& Bladder & 194 & 1.16 & $1.00-1.33$ \\
Penis & Cervix & 19 & 1.84 & $1.11-2.76$ \\
\hline
\end{tabular}

Reference category was a spouse without cancer. The data were adjusted for site age, period, residence and socio-economic level; female data additionally for parity and age at first child-birth. number of cases at these sites, all concordant cancers were increased to 1.15 , but all cancers, including discordant ones, were increased only to 1.03. Results for wives were similar, although the SIRs were somewhat lower: 1.20 for gastric, 1.32 for lung and 1.19 for bladder cancers.

We analysed systematically associations between all discordant sites. In addition to the smoking and sexual behaviour related increases, such as those shown in Table 1, the only other consistent ones, exceeding SIR 1.10 and showing statistical significance, linked stomach and pancreatic cancers, as shown in Table 3. Significant increases were for husbands' gastric cancer by wives' pancreatic cancer (1.21) and for wives' pancreatic cancer by husbands' stomach cancer (1.22). A few other significant associations between the spouses' discordant cancer sites were observed but because they were not confirmed in analysis when the sites were reversed (see last paragraph of Subjects and Methods), the data are not shown.

\section{DISCUSSION}

The present analysis focused on the possible cancer risk factors that could be observed from long-standing spouses with at least 15 years of cohabitation, by definition. The main finding was that spouses did not share cancer risks, with the exception of a few associations that are discussed below. Assuming that the couples share at least some dietary habits and features of life-style, these do not appear to influence cancer risks. This finding was perhaps most remarkable for colorectal cancer for which diet is considered an important factor (Fund, 1997). A weakness of the present study is that we have no dietary data and the study is ecological in this regard. Our data cannot take into account the differences in dietary habits of spouses that persisted through long periods of cohabitation. On the other hand, these data are consistent with the thrust of the migrant studies that suggest that the main shift of the cancer pattern in the new host country takes place between generations one and two (McCredie, 1998; Parkin and Iscovich, 1997). The data on immigrants to Sweden are quite clear-cut on this point. The first generation immigrants who have entered the country in adult age follow a cancer pattern resembling the country of origin, while their Swedish-born children have perfectly adjusted to the Swedish cancer experience (Hemminki and $\mathrm{Li}, 2002 \mathrm{a}, \mathrm{b}$; Hemminki et al, 2002b).

Multiple comparisons are a problem in this kind of study but we could address this by comparing two sites in two ways, as explained at the end of Methods. Among discordant sites that showed increased risks among spouses, sexual and smoking habits were the likely reason for the associations found in Table 1 . Human papilloma virus (HPV) infection is the main etiological factor for cervical cancer and it is also strongly indicated in penile cancer (Dillner et al, 2000; Zur Hausen, 2000). The SIRs between these two cancers were the highest noted for the whole study, over 1.8. The strong association of tobacco- and HPV-related cancers has been a common finding in the Family-Cancer Database, even across two generations (Hemminki et al, 1999, 2001b). Such associations are likely to be an indication of a life-style, for which tobacco smoking, alcohol consumption, sexual promiscuity and divorce are some common denominators (Hemminki and Jiang, 2002b; Kvikstad et al, 1994).

The concordant sites for which the spouses shared risk were stomach, lung and bladder, all with modest SIRs ranging from 1.19 to 1.38 . Tobacco is surely responsible for the concordance of lung and bladder cancer. For stomach cancer, up to $60 \%$ of the cases are attributed to Helicobacter pylori in developed countries and this infection tends to run in families (Bevan and Houlston, 1999; Hamilton and Aaltonen, 2000; Hemminki and Jiang, 2002a; Pisani et al, 1997). Even though the infectivity of Helicobacter may not be high among adults, it is still the main aetiological candidate (Goodman and Correa, 2000); however dietary factors, such as vitamin deficiencies and salty food items, may also contribute (Ekstrom et al, 2000). There was an association 
Table 2 SIR for concordant cancer in spouses

\begin{tabular}{|c|c|c|c|c|c|c|c|c|}
\hline \multirow[b]{2}{*}{ Spouse cancer site } & \multicolumn{4}{|c|}{ Concordant cancer in husbands by wifes' cancer } & \multicolumn{4}{|c|}{ Concordant cancer in wifes by husbands' cancer } \\
\hline & 0 & $\mathbf{E}$ & SIR & $95 \% \mathrm{Cl}$ & 0 & $\mathbf{E}$ & SIR & $95 \% \mathrm{Cl}$ \\
\hline Upper aerodigestive tract & 24 & 15.85 & $|.5|$ & 0.972 .18 & 24 & 16.18 & 1.48 & 0.952 .14 \\
\hline Gastric & 204 & 163.80 & 1.25 & $1.08 \quad 1.42$ & 204 & 169.62 & 1.20 & $1.04 \quad 1.37$ \\
\hline Colon & 414 & 387.21 & 1.07 & 0.971 .17 & 414 & 395.51 & 1.05 & 0.951 .15 \\
\hline Rectum & 118 & 125.22 & 0.94 & $0.78 \quad 1.12$ & 118 & 127.12 & 0.93 & 0.771 .10 \\
\hline Liver & 76 & 63.79 & 1.19 & $0.94 \quad 1.47$ & 76 & 68.79 & 1.10 & $0.87 \quad 1.37$ \\
\hline Pancreas & 76 & 65.99 & 1.15 & $0.91 \quad 1.43$ & 76 & 68.39 & $|| \mid$. & $0.88 \mid .38$ \\
\hline Lung & 406 & 294.46 & 1.38 & $1.25 \quad 1.52$ & 406 & 306.49 & 1.32 & 1.201 .46 \\
\hline Breast & 33 & 25.78 & 1.28 & 0.881 .75 & 33 & 25.50 & 1.29 & 0.891 .77 \\
\hline Kidney & 70 & 71.35 & 0.98 & $0.76 \quad 1.22$ & 70 & 75.10 & 0.93 & 0.731 .16 \\
\hline Bladder & 134 & 108.26 & 1.24 & $\mathrm{I} .04 \mathrm{I} .46$ & 134 & 112.29 & 1.19 & 1.001 .40 \\
\hline Melanoma & 66 & 58.55 & 1.13 & $0.87 \quad 1.42$ & 66 & 58.60 & 1.13 & $0.87|.4|$ \\
\hline Skin & 83 & 72.08 & 1.15 & $0.92|.4|$ & 83 & 72.96 & 1.14 & 0.911 .40 \\
\hline Nervous system & 64 & 60.64 & 1.06 & $0.81 \quad 1.33$ & 64 & 62.28 & 1.03 & 0.791 .29 \\
\hline Thyroid & 6 & 4.05 & 1.48 & 0.532 .90 & 6 & 4.11 & 1.46 & 0.532 .86 \\
\hline Endocrine & 17 & 16.90 & 1.01 & $0.58 \quad 1.54$ & 17 & 17.35 & 0.98 & $0.57 \quad 1.50$ \\
\hline Non-Hodgkin's lymphoma & 56 & 50.77 & 1.10 & 0.831 .14 & 56 & 52.40 & 1.07 & $0.8 \mid 1.37$ \\
\hline Multiple myeloma & 10 & 15.53 & 0.64 & 0.311 .10 & 10 & 15.82 & 0.63 & 0.301 .08 \\
\hline Leukemia & 53 & 49.87 & 1.06 & 0.801 .37 & 53 & 51.83 & 1.02 & $0.77 \quad 1.32$ \\
\hline All, concordant & 1919 & 1661.65 & 1.15 & 1.101 .21 & 1919 & 1712.35 & 1.12 & $1.07 \quad 1.17$ \\
\hline All, any cancer & 71020 & 69240 & 1.02 & $1.02 \quad 1.03$ & 71020 & 68951 & 1.03 & 1.021 .03 \\
\hline
\end{tabular}

All expected numbers were calculated based on site, age, period, residence and socioeconomic level-specific incidence; female data additionally for parity and age at first childbirth. Sites are included if over 5 cases were observed. Bold figures shows that 95\% Cls do not overlay with 1.00 .

Table 3 Aggregation of gastric and pancreatic cancers among spouses

\begin{tabular}{llccc}
\hline Proband: Wife & Cancer in husband & $\mathbf{0}$ & SIR & $\mathbf{9 5 \%} \mathbf{~ C I}$ \\
\hline Stomach & Stomach & 204 & 1.25 & $1.08-1.42$ \\
& Pancreas & 94 & 1.23 & $0.99-1.44$ \\
Pancreas & Stomach & 165 & 1.21 & $1.03-1.40$ \\
Proband: Husband & Cancer in wife & $\mathbf{0}$ & $\mathbf{S I R}$ & $\mathbf{9 5 \%} \mathbf{~ C l}$ \\
Stomach & Stomach & 204 & 1.20 & $1.04-1.37$ \\
& Pancreas & 165 & 1.22 & $1.05-1.42$ \\
Pancreas & Stomach & 94 & 1.16 & $0.94-1.41$ \\
\hline
\end{tabular}

Reference category was a spouse without cancer. The data were adjusted for site, age, period, residence and socio-economic level; female data additionally for parity and age at first child-birth.

between gastric and pancreatic cancers in spouses. Among the known or suggested environmental causes of pancreatic cancer, tobacco smoking, obesity and the resulting diabetes, high caloric intake and alcohol consumption are likely to be shared to some degree by spouses but none of them are important in stomach cancer (Weiderpass et al, 1998).

The present results on spouses have implications for the interpretation of familial risks of cancer, which are usually much

\section{REFERENCES}

Bergstrom A, Pisani P, Tenet V, Wolk A, Adami HO (2001) Overweight as an avoidable cause of cancer in Europe. Int J Cancer 91: 421-430

Bevan S, Houlston RS (1999) Genetic predisposition to gastric cancer. Qjm 92: $5-10$

Dillner J, von Krogh G, Horenblas S, Meijer CJ (2000) Etiology of squamous cell carcinoma of the penis. Scand J Urol Nephrol Suppl 205: 189-193

Doll R, Peto R (1981) The causes of cancer. J Natl Cancer Inst 66: 1191 1309

Dong C, Hemminki K (2001) Modification of cancer risks in offspring by sibling and parental cancers from 2,112,616 nuclear families. Int J Cancer 91: $144-150$ higher than those found in the present study (Dong and Hemminki, 2001; Goldgar et al, 1994; Risch, 2001). Because lifestyles are likely to differ more between parents and offspring than between spouses, familial cancer risks between parents and offspring are more likely to be due to heritable rather than environmental effects. As a reservation, it needs to be considered that childhood and youth may be the most vulnerable period for carcinogenesis. Yet the present results suggest that, with the possible exception of lung cancer, the reported familial risks in cancer that occur in both genders are mainly due to heritable factors, many of which are yet unknown (Hemminki et al, 2001a). In summary, the present analysis on cancer risks among spouses showed no associations, which could not be explained by known risk factors, with the exception of the association between gastric and pancreatic cancers.

\section{ACKNOWLEDGEMENTS}

The Family-Cancer Database was created by linking registers maintained at Statistics Sweden and the Swedish Cancer Registry. The study was supported by the Swedish Cancer Society and King Gustaf V's Jubilee Fund.
Ekstrom AM, Serafini M, Nyren O, Hansson LE, Ye W, Wolk A (2000) Dietary antioxidant intake and the risk of cardia cancer and noncardia cancer of the intestinal and diffuse types: a population-based case-control study in Sweden. Int J Cancer 87: 133-140

Esteve J, Benhamou E, Raymond L (1994) Statistical Methods in Cancer Research Vol. 128. IARC Scientific Publication. Lyon: IARC

Fund WCR (1997) Food, Nutrition and the Prevention of Cancer: a global perspective. Washington, DC: American Institute of Cancer Research

Goldgar DE, Easton DF, Cannon-Albright LA, Skolnick MH (1994) Systematic population-based assessment of cancer risk in first-degree relatives of cancer probands. J Natl Cancer Inst 86: $1600-1007$ 
Goodman K, Correa P (2000) Transmission of Helicobacter pylori among siblings. Lancet 355: $358-362$

Hackshaw A (1998) Lung cancer and passive smoking. Stat Methods Med Res 7: $119-136$

Hamilton S, Aaltonen L (2000) Tumours of the digestive system. In World Health Organization Classification of Tumours pp 314. Lyon: IARC

Hemminki K, Dong C (2000a) Cancer in husbands of cervical cancer patients Epidemiology 11: 347-349

Hemminki K, Dong C (2000b) Life style and cancer: protection from a cancer-free spouse. Int J Cancer 87: 308 -309

Hemminki K, Dong C, Frisch M (2000a) Tonsillar and other upper aerodigestive tract cancers among cervical cancer patients and their husbands. Eur J Cancer Prev 9: 433-439

Hemminki K, Dong C, Vaittinen P (1999) Familial risks in cervix cancer: is there a hereditary component? Int J Cancer 82: 775-781

Hemminki K, Dong C, Vaittinen P (2001a) Cancer risks to spouses and offspring in the Family-Cancer Database. Genet Epidemiol 20: 247 -257

Hemminki K, Jiang Y (2002a) Familial and second gastric cancers: a nation wide epidemiologic study from Sweden. Cancer 94: 1157-1165

Hemminki K, Jiang Y (2002b) Life style and cancer: effect of divorce. Int J Cancer 98: $316-319$

Hemminki K, Li X (2002a) Cancer risks in childhood and adolescence among second generation immigrants to Sweden. Br J Cancer (in press)

Hemminki K, Li X (2002b) Cancer risks in second generation immigrants to Sweden. Int J Cancer 99: 229-237

Hemminki K, Li X, Mutanen P (2001b) Familial risks in invasive and in situ cervical cancer by histological type. Eur J Cancer Prev 10: 83-89

Hemminki K, Li X, Czene K (2002b) Cancer risks in first generation immigrants to Sweden. Int J Cancer 99: 218-228

Hemminki K, Li X, Plna K, Granström C, Vaittinen P (2001c) The nationwide Swedish Family-Cancer Database: updated structure and familial rates. Acta Oncol 40: $772-777$

Hemminki K, Lönnstedt I, Vaittinen P, Lichtenstein P (2001d) Estimation of genetic and environmental components in colorectal and lung cancer and melanoma. Genet Epidemiol 20: $107-116$
IARC (1990) Cancer: Causes, Occurence and Control Vol. 100. IARC Sci Publications. Lyon: IARC

IARC (1995) Human papillomaviruses Vol. 64. IARC Monographs on the Carcinogenic Risks to Humans. Lyon: IARC

IARC (2002) Weight Control and Physical Activity Vol. 6. IARC Handbooks of Cancer Prevention. Lyon: IARC

Kvikstad A, Vatten LJ, Tretli S, Kvinnsland S (1994) Widowhood and divorce related to cancer risk in middle-aged women. A nested case-control study among Norwegian women born between 1935 and 1954. Int J Cancer 58: $512-516$

Lichtenstein P, Holm N, Verkasalo P, Illiado A, Kaprio J, Koskenvuo M, Pukkala E, Skytthe A, Hemminki K (2000) Environmental and heritable factors in the causation of cancer. $N$ Engl J Med 343: $78-85$

McCredie M (1998) Cancer epidemiology in migrant studies. Recent Results Cancer Res 154: $298-305$

Parkin DM, Iscovich J (1997) Risk of cancer in migrants and their descendants in Israel: II. Carcinomas and germ-cell tumours. Int J Cancer 70: $654-660$

Peto J (2001) Cancer epidemiology in the last century and the next decade. Nature 411: $390-395$

Pisani P, Parkin D, Munoz N, Ferlay J (1997) Cancer and infection: estimates of the attributable fraction in 1990. Cancer Epidemiol Biomarkers Prev 6 : $387-400$

Risch N (2001) The genetic epidemiology of cancer: interpreting family and twin studies and their implications for molecular genetic approaches. Cancer Epidemiol Biomarkers Prev 10: 733-741

Weiderpass E, Partanen T, Kaas R, Vainio H, Porta M, Kauppinen T, Ojajärvi A, Boffetta P, Malats N (1998) Occurence, trends and environmental etiology of pancreatic cancer. Scand J Work Environ Health 24: 165-174

Zur Hausen H (1999) Viruses in human cancers. Eur J Cancer 35: 1174-1181

Zur Hausen H (2000) Papillomaviruses causing cancer: evasion from hostcell control in early events in carcinogenesis. J Natl Cancer Inst 92: $690-$ 698 